
\title{
CIÊNCIANATURA
}

\section{Cura ou conservação: um dilema socioambiental na formação continuada de professores}

\author{
Cure or conservation: a socio-environmental dilemma in continuing teacher training
}

Lidiane Amaral Barbosa, Elinete Oliveira Raposo e Nadia Magalhães da Silva Freitas

Universidade Federal do Pará, PA, Brasil

Instituto de Educação Científica e Matemática

Programa de Pós-Graduação em Educação em Ciências e Matemáticas

\section{Resumo}

Muitos são os desafios socioambientais contemporâneos, a saber: qualidade socioambiental e a sustentabilidade das cidades, mitigação e enfrentamento da mudança climática, gestão da água e dos resíduos sólidos, gestão das florestas, demanda crescente e alternativas energéticas, entre outros. Nesse contexto, a pesquisa foi conduzida pela seguinte questão: em que termos professores, em processo de formação continuada, fundamentam sua tomada de decisão frente a um dilema socioambiental envolvendo o tema floresta? A pesquisa apresentou abordagem qualitativa e se deu no contexto de um processo de formação continuada de professores da educação básica. As análises apresentadas referiram-se a um estudo de caso (fictício, mas verossimil), intitulado "Cura ou conservação: as questões de saúde humana e o ecossistema". Os posicionamentos dos professores congregaram conhecimentos de duas áreas: ciências naturais e ciências sociais, aproximando-as. Consideraram aspectos como identidade, cultura e conhecimentos tradicionais, esquivando-se de posicionamentos que exorcizam a alteridade e a soberania dos conhecimentos científicos, em relação aos demais. Para além da sua formação específica, os professores integraram conhecimentos, em uma autêntica atitude interdisciplinar na consideração do dilema socioambiental proposto na formação. As discussões dos professores foram legítimas, seus posicionamentos pertinentes e mostraram-se atuais, ao considerarmos as preocupações que incidem no campo socioambiental.

Palavras chave: Formação de professores. Desafios socioambientais. Floresta.

\section{Abstract}

There are many contemporary socio-environmental challenges: socio-environmental quality and sustainability of cities, mitigation and coping with climate change, water and solid waste management, forest management, growing demand and energy alternatives, among others. In this context, the research was driven by the following question: in what terms teachers, in a process of continuous formation, base their decisionmaking on a socio-environmental dilemma involving the forest theme? The research was based on a qualitative approach and was carried out in the context of a process of continuous training of teachers. The analyzes refer to a case study (fictitious, but credible) entitled "Cure or conservation: human health and the ecosystem". The positions of the teachers brought together knowledge from two areas: natural sciences and social sciences, approaching them; considered aspects such as identity, culture and traditional knowledge, avoiding positions that exorcize the alterity and the sovereignty of scientific knowledge in relation to others. Despite of to their specific academic education, teachers integrated knowledge, in an authentic interdisciplinary attitude in the consideration of the socio-environmental dilemma proposed in the training. The teachers' discussions were legitimate, their positions pertinent and they were actual, considering the concerns that are manifested in the environmental field.

Keywords: Teacher training. Socio-environmental challenges. Forest. 


\section{Introdução}

A intensa transformação vivenciada pela sociedade, a partir do século XX, tem colocado em foco as questões socioambientais, transformando-as em uma preocupação legítima. Porém, foi na década de 1960 que a crise ambiental passou a ganhar mais evidência com o desenvolvimento da consciência ambiental, decorrente do lançamento do livro Primavera Silenciosa, de Rachel Carson (CARSON, 2010). Entretanto, de acordo com Jollivet e Pavé (2002), foi somente no início da década de 1970 que as consequências danosas das intervenções humanas, no funcionamento da biosfera, começaram a ser divulgadas de maneira mais ampla, principalmente após a Conferência das Nações Unidas sobre o Meio Ambiente Humano, realizada em Estocolmo, em 1972 (SACHS, 2008).

Para Tristão (2004, p. 23), a “[...] crise ambiental não é somente uma crise ecológica e sim uma crise do pensamento da civilização ocidental". Para a referida autora, estamos engendrados na "[...] racionalidade formal e instrumental fundamentada no aspecto econômico" (TRISTÃO, 2004, p. 23). Vivemos em tempos em que "[...] a maioria das sociedades aderiu à luta competitiva pela existência, acredita no progresso como crescimento econômico e tecnológico [...]" (VASCONCELOS et al., 2014 , p. 247). Essa conformação societária tem gerado questionamentos em relação à racionalidade econômica e tecnológica dominante (BIGLIARD; CRUZ, 2007).

É nesse contexto que emergem alguns questionamentos, tais como a racionalidade do pensamento da atual civilização, o homem como centralidade do universo, os valores de dominação da natureza, o processo incontrolável e insustentável de produção, o reforço à cultura do consumismo, a constituição de um mundo economizado, entre outros (LEFF, 2010). Assim,

A solução da crise ambiental - crise global e planetária - não poderá dar-se somente pela via de uma gestão racional da natureza e do risco de mudança global. A crise ambiental nos leva a interrogar o conhecimento do mundo, a questionar esse projeto epistemológico que buscou a unidade, a uniformidade e a homogeneidade; esse projeto que anuncia um futuro comum, negando o limite, o tempo, a história, a diferença, a diversidade, a outridade (LEFF, 2010, p. 20).

Neste ponto, é importante salientar que a racionalidade ambiental exige a compreensão da conexão existente entre natureza e economia. Entretanto, por um lado, apresenta-se o capitalismo com suas estruturas de poder e de dominação de extração dos recursos, orientado pelas regras quantitativas do mercado, sem levar em consideração os transtornos futuros. E, ainda, profundamente associados à concepção de desenvolvimento e crescimento econômico, inclusive no que diz respeito à conformação das relações de desigualdade entre países centrais e periféricos (SILVA, 2010). De outro lado, observa-se a consciência ambientalista, a qual busca valorizar os recursos naturais, orientada pela questão conservacionista destes mesmos recursos, questionando a lógica do capital, apontando os limites que a natureza tem para se refazer e garantir o futuro das próximas gerações (STAHEL, 2009).

Os educadores têm um papel determinante na discussão das questões socioambientais, notadamente quando pensamos que estes assumem, para si, a tarefa de formação de pessoas. Nesse sentido, o trabalho de pesquisa ora apresentado, conduziu-se pela seguinte questão: em que termos, professores em processo de formação continuada fundamentam sua tomada de decisão frente a um dilema socioambiental, envolvendo o tema floresta? Nesse contexto, consideramos como argumento nuclear da proposição de formação continuada de professores, que a compreensão das questões socioambientais na/da Amazônia, notadamente em relação a sua floresta, só poderá concretizar-se mediante apreensão interdisciplinar, ou seja, a partir da consideração dos múltiplos contextos inter-relacionados. Nesse âmbito, as metodologias ativas representam processos construtivos da percepção da realidade ambiente, na medida em que os sujeitos são desafiados a ponderar sobre as múltiplas dimensões concernentes a um dado objeto de estudo, em uma perspectiva crítica e reflexiva.

\section{Contextos da sustentabilidade: a floresta como um desafio socioambiental contemporâneo}

Para Nascimento (2012), a ideia de sustentabilidade tem duas origens: a primeira, na biologia, mais precisamente na ecologia e a segunda, na economia. Na biologia, o termo é utilizado na ecologia relacionando-a a capacidade de resiliência dos ecossistemas, após agressões antrópicas, como desflorestamento, queimadas ou eventos naturais, como terremotos, tsunamis, dentre outros. A dimensão ambiental é, geralmente, conforme Nascimento (2012), a primeira a ser lembrada e citada. Inclusive, muitas ações são pautadas e limitadas apenas a esse aspecto. Para Nascimento (2012), essa dimensão "[...] supõe que o modelo de produção e consumo seja compatível com a base material em que se assenta a economia, como subsistema do meio natural", ou seja, a produção e o consumo devem ser realizados de forma que os ecossistemas possam exercer sua capacidade de resiliência.

No campo da economia, a ideia de sustentabilidade surge em conjunção com o termo desenvolvimento (desenvolvimento sustentável), em decorrência da "[...] percepção crescente ao longo do século XX de que o padrão de produção e consumo em expansão no mundo, sobretudo no último quarto desse século, não tem possibilidade de perdura" (NASCIMENTO, 2012, p. 51). De acordo ainda com Nascimento (2012, p. 51), “[...] ergue-se, assim, a noção de sustentabilidade sobre a percepção da finitude dos recursos naturais e sua gradativa e perigosa depleção”. 
Na compreensão de Nascimento (2012, p. 56), para que uma sociedade possa se constituir sustentável é mister que todos os cidadãos possuam o mínimo necessário para uma vida digna, e que ninguém aspire bens, recursos naturais e energéticos que sejam prejudiciais a outros. Em outros termos, para que uma sociedade seja sustentável é preciso "[...] erradicar a pobreza e definir o padrão de desigualdade aceitável, delimitando limites mínimos e máximos de acesso a bens materiais. Em resumo, implantar a velha e desejável justiça social” (NASCIMENTO, 2012, p. 56).

Nessa direção, Leff (2012, p. 246) afirma o seguinte:

Os desafios do desenvolvimento sustentável implicam a necessidade de formar capacidades para orientar um desenvolvimento fundado em bases ecológicas, de equidade social, diversidade cultural e democracia participativa. Isto estabelece o direito à educação, a capacitação e a formação ambiental como fundamentos da sustentabilidade, que permita cada pessoa e cada sociedade produzir e apropriar-se de saberes, técnicas e conhecimentos para participar na gestão de seus processos de produção, decidir sobre suas condições de existência e definir sua qualidade de vida.

Entendemos que Leff $(2010 ; 2012)$ evoca o desenvolvimento sustentável como uma perspectiva para o enfrentamento da crise que ora se apresenta. Note-se que o autor agrega aspectos/condições importantes a sua configuração, tais como bases da dinâmica ecológica como norma do sistema econômico, princípios éticos na consideração do homem e da natureza, equidade social, respeito à diversidade cultural, democracia, entre outros.

Nesse sentido, Afonso (2006) afirma que a sustentabilidade precisa ser entendida como um processo contínuo que necessita da participação de todos os setores da sociedade para que possa ocorrer de fato. Esse envolvimento é fundamental porque "Nenhum aspecto da vida é deixado à margem do desenvolvimento sustentável, assim como o desenvolvimento que seja cada vez mais sustentável repercutirá em todas as facetas da vida” (UNESCO, 2005, p. 41).

A ideia de sustentabilidade deve ser entendida como um processo de mudança e de transformação, com valor social, na consideração das necessidades fundamentais da coletividade (as pessoas como propósito final e não o mercado), bem como na atenção aos aspectos socioculturais e ambientais; e, ainda, como um processo de ampliação das oportunidades sociais e do desenvolvimento das potencialidades humanas, ou seja, o desenvolvimento fundamentado no pressuposto da sustentabilidade - sustentabilidade como qualidade do desenvolvimento (FONSECA NETO; FREITAS; FREITAS, 2017).

Os temas socioambientais locais podem ser o ponto de partida para discussões sobre sustentabilidade e, consequentemente, para a introdução e o alargamento das discussões de temas mais globais, ressaltando sempre a conexão entre os ecossistemas, alertando que problemas locais são também globais e os globais são igualmente locais. Entendemos que no ensino das ciências, muitos conteúdos e temas são propícios à problematização. Destacamos, nesse contexto, aqueles relativos às discussões sobre a floresta e a sustentabilidade, os quais se apresentam como componentes transversalizantes a ciências naturais, de modo que também contribui para formar novas consciências que sejam capazes de contribuir para uma sociedade melhor (SCHWINGEL; UHMANN; HERMEL, 2016).

Na região Norte, por exemplo, a destruição da floresta impacta não só a população local, mas todo o restante do país e do mundo. Destruir a floresta amazônica significa destruir não só a biodiversidade, mas também modos de vida; significa diminuir ou até mesmo anular a possibilidade de descobertas de cura de várias doenças, uma vez que a floresta vem sendo destruída antes mesmo de ter seus valiosos recursos químicos naturais descobertos (KOHLHEPP, 2002).

A compreensão da forma como nossa floresta Amazônica foi e continua sendo tratada, pode ser avaliada ao recorrermos à história da ocupação da nossa região. Historicamente, o processo de ocupação foi conturbado, pois não se reconhecia (como ainda não se reconhece) a vocação da região - o que se via e servia de atrativo eram as grandes extensões de terras distantes dos grandes centros comerciais e, portanto, com menor valor, assim, o resultado foi a atração de grandes pecuaristas (BECKER, 2005).

Assim, nossa floresta passou a ser derrubada para dar espaço a pastos (FERREIRA; SALATI, 2005). Gonçalves (2009) ressalta que há uma grande contradição nessa atividade, pois se, por um lado, a pecuária aparece como atividade economicamente mais viável do ponto de vista capitalista de curto prazo, de outro é um desastre ecológico e sociocultural, pois o desmatamento destrói as bases naturais de sobrevivência das populações.

Segundo Viana (2006), as florestas passaram, então, a ser tratadas pelos polices makers como um estorvo que precisava ser retirado para a expansão da agropecuária. Inicia-se, assim, a retirada da vegetação para a abertura de áreas para a instalação de projetos agropecuários, que começaram, então, a modificar o cenário Amazônico. Desse modo, os “"[...] projetos agropecuários financiados pelo governo militar representavam o primeiro movimento de um processo contínuo de formação de extensos domínios privados no interior da Amazônia, trazendo graves consequências sociais e ambientais para a região" (LIMA; POZZOBON, 2005, p. 63).

Sabemos, portanto, que as florestas são fundamentais às nossas vidas e ao ambiente. Mas, em função da intensa intervenção humana, o tamanho das florestas tem sido alterado, basicamente pela desatenção quanto aos limites de sua exploração (MORAN, 2010). Assim, o que percebemos é que muito pouco se tem feito para conservar a floresta e/ou recuperar suas áreas degradadas. A Amazônia se tornou um campo de cobiça, uma fonte de lucros fáceis, com explorações nocivas à população (HOSANNAH, 2015). Pesquisas revelam que na Amazônia muitas espécies já não existem mais; muitos genes foram perdidos, assim como a cultura do povo que habita a floresta está constantemente ameaçada pelo progresso científico desordenado - os 
conhecimentos tradicionais são biopirateados e patenteados por empresas multinacionais e instituições científicas, animais e plantas também e, o que é mais injusto, a população tradicional não usufrui dos lucros do sistema capitalista e das multinacionais (KAGEYAMA 2010; HATHAWAY, 2008).

Nas últimas décadas do século XX e início do século XXI, a economia da Amazônia tem sido baseada na agroindústria da soja, da pecuária e na instalação de indústrias exportadoras da Zona Franca de Manaus, que se fixaram na região para produzir mercadorias - motocicletas, produtos eletrônicos, dentre outros, - empreendimentos que não possuem nenhuma relação com a realidade da região. Nesse processo de ocupação, pouco se pensou na possibilidade de implantação de indústrias que utilizassem produtos da floresta, a exemplo da castanha, madeira, borracha, palmito, óleos medicinais etc., como matéria-prima (VIANA, 2006).

É esse contexto de ocupação e das possibilidades de mudanças no processo de exploração da floresta, que acreditamos que o tema "floresta" deva ser discutido. Assim, pensando a respeito do papel da educação, afirmo, no contexto de constantes metamorfoses, a importância de se refletir criticamente sobre o valor da floresta e todos os seus agentes. Por sua vez, abordar as questões de sustentabilidade implica, necessariamente, discutir as relações que se estabelecem entre Ciência, Tecnologia e Sociedade (CTS), ao se considerar os seguintes argumentos:

[...] 1) o momento socioambiental atual é tenso, quando se considera os limites do planeta; 2) a tecnologia, produto do conhecimento científico, parece não ter sido construída em vinculação a uma ética que indique o sentido e os limites de sua difusão e aplicação no meio social; 3 ) a educação científica passou por um período de 'cegueira' em relação às consequências que o uso do conhecimento científico poderia ocasionar à sociedade, em virtude do obscurantismo técnico, fomentado pelo cartesianismo (VASCONCELOS; FREITAS, 2012, p. 91).

Neste ponto, reportamo-nos à floresta considerada uma das mais importantes do planeta - a floresta Amazônica. Trata-se de uma das últimas reservas vegetais do planeta e, ao levarmos em conta o exemplo de exploração ocorrida nas matas brasileiras, em cinco séculos, a questão da floresta mostrar-se-á preocupante. Deve-se reconhecer, pelo menos no discurso, que a riqueza maior da Amazônia é a sua biodiversidade, sua floresta, enfim, seu capital natural (ARAGÓN, 2008). Por outro lado, temos que considerar que a floresta não deve se constituir barreira que dificulte o desenvolvimento econômico da Amazônia (BATISTA, 2007).

Destacamos, neste ponto, que se reconhecer como parte da natureza e posicionar-se frente às problemáticas do seu próprio contexto social são habilidades que podem ser potencializadas na educação, notadamente aquela que se propõe a educar para a sustentabilidade, isso porque a educação para a sustentabilidade estabelece-se:

[...] como organizadora de uma atmosfera, capaz de promover habilidades, competências e atitudes que possam sustentar o aprendizado com postura crítica, frente às constantes transformações pela qual vem passando a sociedade, nem sempre favoráveis à comunidade de vida (FONSECA NETO; FREITAS; FREITAS, 2017, p. 134).

Ampliando a ideia, podemos nos referir ao que está posto nas Diretrizes Curriculares Nacionais para a Educação Básica (BRASIL, 2013, p. 522), a saber:

A visão socioambiental complexa e interdisciplinar analisa, pensa, organiza o meio ambiente como um campo de interações entre a cultura, a sociedade e a base física e biológica dos processos vitais, no qual todos os elementos constitutivos dessa relação modificam-se dinâmica e mutuamente. Tal perspectiva considera o meio ambiente como espaço relacional, em que a presença humana, longe de ser percebida como extemporânea, intrusa ou desagregadora, aparece como um agente que pertence à teia de relações da vida social, natural, cultura, e interage com ela.

Nesse sentido, compreendemos a importância de se conhecer mais a vida e sobre sua condição singular na natureza, o que permite ao aluno se posicionar acerca de questões relativas aos campos social, ambiental, econômico, cultural, entre outros, na consideração do pressuposto da sustentabilidade. Entendemos que a perspectiva é contribuir para pensar mudanças frente à situação existente, possibilitando a compreensão, por exemplo, da importância da floresta, no que concerne a sua conservação, a manutenção da integralidade do ecossistema, entre outros aspectos.

\section{Formação de professores:}

\section{dos contextos gerais aos contextos socioambientais - a complexidade como ponto de inflexão}

A importância atribuída aos professores para a educação de qualidade é largamente reconhecida, mas a educação de qualidade constitui-se ainda desafio, notadamente a formação de professores (inicial e continuada). São vários os autores que discutem a formação continuada de professores, os quais a apresentam sob diferentes enfoques (RIBAS, CARVALHO; ALONSO 2003; CARVALHO; GIL-PÉREZ, 2011; MALDANER, 2003; IMBERNÓN, 2010). Entretanto, não pretendemos, aqui, discorrer sobre as várias perspectivas de formação de professores ou tratar o tema segundo seus aspectos históricos, mas, tão somente, refletir 
sobre a formação de professores, em tempos que se faz necessária a adoção de novos paradigmas que possam acompanhar as transformações crescentes da atual sociedade.

É neste ponto que destacamos que o atual momento está fortemente marcado por mudanças paradigmáticas. Interessanos, aqui, aquelas que se inscrevem no campo educacional e ambiental. Compreendemos que uma aprendizagem crítica e transformadora deve pautar-se por paradigmas inovadores (FLACH; BEHRENS, 2008). Contudo, é no contexto do paradigma tradicional que a "[...] ação docente concentra-se em criar mecanismos que levem a reproduzir o conhecimento historicamente acumulado e repassado como verdade absoluta" (BEHRENS; OLIARI, 2007, p. 59). E, ainda hoje, a escola é impregnada pela mera transmissão de informação (CHASSOT, 2011). Então, entendemos que esse paradigma apresenta processos disjuntivos que certamente levaram (e têm levado) as sociedades a colapsos de várias ordens. No nosso entendimento, a crise ambiental é uma das manifestações disjuntivas desse paradigma, ou seja,

[...] uma falha nos modos de compreender o mundo de construção de conhecimentos [...] do modo hegemônico de produção do mundo que desenhou formas de insustentáveis de habitabilidade da Terra e desencadeou um processo progressivo de degradação ecológica do planeta (LEFF, 2016, p.13).

Cabe destacar, neste ponto, que

[...] o paradigma newtoniano cartesiano não foi um erro, e sim foi importante para constituir uma trajetória para a evolução do pensamento humano. Este paradigma focalizou a especialização, e propôs uma visão que separou mente, corpo e espírito para examiná-los especificadamente. Mas tal forma de ver o conhecimento apresentou-se limitada diante da sociedade atual que teve um progresso científico-tecnológico grande, ou seja, o paradigma vigente não consegue mais contemplar tal realidade (FLACK; BERHENS, 2008, p. 10124).

Então, surge a proposição de adoção de um paradigma inovador, qual seja:

O Paradigma da Complexidade, sistêmico ou emergente propõe que o homem seja visualizado como um ser indiviso, numa perspectiva de aliança e encontro, buscando uma ação pedagógica que leve a produção do conhecimento e busque formar um indivíduo sujeito de sua própria história (FLACK; BERHENS, 2008, p. 10124).

Para o enfrentamento das questões socioambientais, a educação é considerada um dos caminhos. Não qualquer educação, mas aquela que realize aprofundamentos, interconexões, considere a multidimensionalidade dos objetos de estudo, pondere sobre a realidade local. Trata-se de uma abordagem pautada pelo paradigma da complexidade.

A despeito desses aspectos, deparamo-nos com processos de formação frágeis para a abordagem da dimensão socioambiental. A fragilidade reside na visão reducionista da problemática ambiental (QUEIROZ; PLÁCIDO, 2012; WATANABE-CARAMELLO; KAWAMURA, 2014). Em contextos amazônicos, faz-se necessária também, uma formação adequada para abordagem crítica dos desafios socioambientais contemporâneos. Tal afirmativa pauta-se em resultados de pesquisa que indicaram que alguns professores amazônidas filiam-se a "[...] pensamentos de atores externos, que vêm [...] à possibilidade de interferir e, até mesmo dominar o espaço amazônico de acordo com interesses próprios" (VASCONCELOS; FREITAS, 2011, p.11).

Nesse sentido, uma estratégia pertinente é eleger questões ambientais candentes, notadamente do âmbito local, em um cenário real, de modo que se manifestem a gênese da vontade política e de tomada de decisão (TAVOLARO, 2005). A formação de professores deve ser desenvolvida a partir de processos reflexivos que levem em conta "[...] uma metodologia de formação centrada em casos, trocas, debates, leituras, trabalho em grupo, incidentes críticos, situações problemáticas dentre outras" (IMBERNÓN, 2010, p. 65-66).

\section{Caminhos metodológicos da pesquisa}

A pesquisa apresentou abordagem qualitativa, pois se estabeleceu a partir das relações humanas e, portanto, a subjetividade fez parte do processo de pesquisa (MINAYO, 2016). Segundo Moraes (2003), a pesquisa qualitativa parte de textos preexistentes ou da produção de conteúdo voltado à análise a partir de observações e/ou entrevistas, ou seja, a pesquisa qualitativa visa:

[...] aprofundar a compreensão dos fenômenos que investiga a partir de uma análise rigorosa e criteriosa desse tipo de informação, isto é, não pretende testar hipóteses para comprová-las ou refutá-las ao final da pesquisa; a intenção é a compreensão (MORAES, 2003, p. 191).

Nesse sentido, é importante destacar que a pesquisa se deu no contexto de um projeto de pesquisa mais amplo intitulado "Coletivo de Estudos e Práticas em Educação para o Desenvolvimento Sustentável”, precisamente no âmbito de um processo 
de formação continuada de professores, o qual tinha como objetivo problematizar os recentes desafios socioambientais. Nosso objeto de análise referiu-se a uma das atividades formativas que envolvia o tema floresta.

A atividade constituía-se, especificamente, de um estudo de caso (fictício, mas verossímil), conforme é detalhado a seguir, como uma estratégia de ensino e de aprendizagem, também para o contexto da formação de professores. Neste ponto, cabe referir que o Método de Estudo de Caso é uma vertente do método Problem Basead Learning (PBL), estratégia que teve sua origem no final da década de 1970, na Escola de Medicina da Universidade de McMaster em Ontário, Canadá - o objetivo era possibilitar aos alunos o contato com problemas reais e, assim, propiciar o desenvolvimento da autonomia do aluno, por meio do estudo autodirigido, além de desenvolver o pensamento crítico (SÁ; QUEIROZ, 2010).

O estudo de caso é um método de ensino que pode ser utilizado com eficiência, a nosso ver, tanto na formação inicial como na formação continuada de professores, pois é um método que favorece a própria aprendizagem e a investigação de

[...] aspectos científicos e sociocientíficos, presentes em situações reais ou simuladas, de complexidade variável. Este método consiste na utilização de narrativas sobre dilemas vivenciados por pessoas que necessitam tomar decisões importantes a respeito de determinadas questões (SÁ; QUEIROZ, 2010, p. 12).

Desse modo, fizemos uso de um caso fictício, mas verossímil, intitulado “Cura ou conservação: as questões de saúde humana e o ecossistema". A narrativa do caso foi apresentada aos professores, no processo de formação. Indicamos, na narrativa, que havia pretensão de uma multinacional farmacêutica em extrair um bioativo antitumoral (paclitaxel - nome comercial taxol), presente no Taxus brevifolia, espécime florestal encontrado, curiosamente, em terras indígenas. Na elaboração do estudo de caso, utilizamos o recurso da narrativa fictícia, cujos personagens (representantes da comunidade indígena e não indígena, um instituto de pesquisa, órgão governamental, ligado ao meio ambiente e a própria multinacional farmacêutica) estavam enredados no dilema.

Informamos que o taxol era uma das poucas drogas que mostrava excelência eficácia no tratamento de cânceres que cresciam rapidamente, e que estava presente na casca da árvore, e a remoção da casca automaticamente mataria a árvore, o que implicaria na sua depleção, entre outros desdobramentos. Chamamos atenção para o fato de que a comunidade indígena utilizava essa árvore (e seus produtos) na confecção de artesanato, bem como nas cerimônias tradicionais, além de se constituir alimento de alguns animais que, por seu turno, eram utilizados na alimentação da comunidade.

Assim constituiu-se o enredo e, de acordo como Sá e Queiroz (2010), sua construção tem por objetivo levar à compreensão dos fatos, das circunstâncias, dos valores e dos contextos que permeiam a situação-problema, para, ao final, motivar a decisão para o caso. Desse modo, com o dilema estabelecido, "cura ou conservação", na consideração do recurso florestal Taxus brevifolia, os professores foram convidados a se posicionarem, nos seguintes termos: que decisão vocês tomariam em relação à exploração do espécime Taxus brevifolia? Que justificativas vocês apresentariam para fundamentar sua decisão?

Os sujeitos de pesquisa foram representados por seis professores, que desenvolveram, efetivamente, a atividade (o estudo de caso), quais sejam: cinco professores da educação básica; destes, três são Licenciadas em Biologia, um em História, uma em Geografia e, ainda, uma professora da educação superior que atua no ensino de ciências, além de uma das formadoras que também colaborou com as discussões. As produções desses professores constituíram-se nos dados da pesquisa, especificamente os textos que apresentavam a decisão do caso, bem como as transcrições das falas audiogravadas, decorrentes do processo de discussão coletiva, ainda relativas às decisões. Neste artigo, os professores são apresentados por nomes fictícios, referentes a espécimes vegetais, como forma de não identificação dos sujeitos da pesquisa.

Os referidos dados foram submetidos à análise interpretativa (ESTEBAN, 2010; CRESWELL, 2010). Identificamos, nos textos, os excertos que apresentavam a decisão e os respectivos elementos que fundamentavam a referida decisão, tais como pressupostos, reflexões, avaliações, críticas etc., correspondendo às interlocuções empíricas dos sujeitos de pesquisa. E, considerando essas interlocuções, trouxemos manifestações de autores, pertinentes à área, relativas aos elementos que compunham a decisão, representando as interlocuções teóricas. Por fim, “organizamos” o diálogo entre as interlocuções empíricas e teóricas, acrescidas de nossas próprias manifestações, resultando nas análises.

\section{Cura ou conservação: as questões de saúde humana e o ecossistema - decisões e fundamentações de um estudo de caso na formação de professores.}

Na contemporaneidade, somos colocados cotidianamente frente a vários dilemas, os quais exigem uma tomada de decisão. Os objetos de decisão, de natureza diversa, mostram-se, no atual contexto de desenvolvimento da sociedade, cada vez mais complexo, exigindo pensar sobre as múltiplas dimensões que os constituem. O importante não é se posicionar contra ou a favor, aleatoriamente, em relação a um dado assunto, mas, sim, apresentar argumentos que balizem as decisões e as escolhas. Essa foi a perspectiva adotada na formação continuada de professores, ao trazer o dilema em questão, como estratégia de formação e de pesquisa. 
Trazemos, nesta seção, as decisões e as fundamentações assumidas pelos professores na formação, em relação ao caso (dilema). Assim, a professora Jasmim se mostrou contrária à extração do taxol. Para fundamentar sua decisão, a referida professora fez algumas ponderações, apresentadas abaixo. Vejamos:

[...] tem que ser levada em consideração algumas questões [...] a conservação das espécies, valores e conhecimentos das comunidades tradicionais, respeito com as futuras gerações e justiça social [...] (PROFESSORA Jasmim).

A professora Jasmim refere que múltiplos aspectos devem ser considerados, incorporando a perspectiva multidimensional, complexa, na análise do objeto de estudo. Temos que considerar, inicialmente, que cada uma das milhares de espécies da natureza desempenha funções específicas, com contribuições que colaboram com o equilíbrio dinâmico do ecossistema. Logo, se uma dada espécie é extinta, ocorre a potencialização da extinção de outras espécies. Por sua vez, pode ocorrer o comprometimento da variabilidade de genes existentes na natureza, interferindo, assim, na dinâmica dos sistemas naturais (CONSERVAÇÃO INTERNACIONAL, 2010). Então, a apreensão da Professora Jasmim é pertinente.

O excerto abaixo nos remete à compreensão de que os aspectos biológicos, envolvidos na questão da remoção da espécie, não são identificados, a saber:

Aí eu relato a fala do senhor Francisco que é um dos representantes da tribo que ele coloca assim: 'não sabemos o que esta remoção vai fazer para o resto das plantas e animais'. Então, fica bem claro que há incertezas quanto à questão das consequências para o meio ambiente (PROFESSORA Jasmim).

A presente abordagem nos direciona a um importante princípio. Trata-se, do princípio da precaução, “[...] presentemente um princípio fundamental da regulação ambiental em muitos países” (GONÇALVES, 2013, p. 122). O princípio da precaução traz como pressuposto que em "Existindo dúvida sobre a possibilidade futura de dano ao homem e ao ambiente, a solução deve ser favorável ao ambiente e não a favor do lucro imediato - por mais atraente que seja para as gerações" (MIRRA, 2001, p. 11). O princípio da precaução, portanto, tem uma finalidade ainda mais nobre do que a própria prevenção, já que, em última análise, este, estaria contido naquele.

Realizamos a discussão do significado desse princípio, no contexto das questões socioambientais. Discutir essas questões no ensino e na formação de professores é de extrema necessidade, pois uma sociedade não pode viver alheia aos problemas que as cercam sem refletir sobre eles, ajudando a encaminhar soluções para um futuro previsível, e é no espaço da educação que este campo se torna fértil.

Em continuidade às análises sobre as ponderações da Professora Jasmim, podemos referir que a mesma traz reflexões importantes na perspectiva da sustentabilidade, agregando preocupações com as gerações vindouras, já que a retirada da espécie vegetal em questão pode extingui-la, a saber:

[...] Então eu pensei, em nenhum momento eu percebi a preocupação no tratamento [...] das pessoas que vierem a adoecer com câncer, como que é? Não vai ter mais individuo não vai ter mais essas árvores para poder produzir o taxol. Então como é que vai ser o tratamento dessas mulheres se não tiverem esse fármaco né? De todos né, pensando nas futuras gerações (PROFESSORA Jasmim).

A Professora mostra-se receosa quanto à produção do fármaco, indagando-se sobre as reais consequências para as futuras gerações, ao considerar que a indústria farmacêutica se propõe a produzir uma quantidade limitada do fármaco, à custa da depleção da espécie em questão na localidade. A preocupação é plausível, pois, de acordo com Ganem e Drummond (2011, p. 7),

O planeta vive uma crise de biodiversidade, caracterizada pela perda acelerada de espécies e de ecossistemas inteiros. Essa crise agrava-se com a intensificação do desmatamento nos ecossistemas tropicais, onde se concentra a maior parte da biodiversidade.

Consideramos que as preocupações da professora Jasmim são relevantes, pois a exploração excessiva aponta para um agravamento da crise e possíveis consequências de riscos para as futuras gerações, caso ocorra a extinção da espécie. Tal preocupação reverberou junto aos professores, levando-os a refletir sobre a situação. Em realidade, o desafio é conseguir uma coexistência sustentável entre biodiversidade, biotecnologia e saúde, a qual reflita a relação e a integração da natureza com a sociedade. Esse modelo deve ser interativo, cooperativo e inter-relacionado e dependente de um maior debate com a sociedade (GARCIA, 1995, p. 496), aspectos que foram considerados no desdobramento das discussões entre os professores na formação.

Entendemos que a professora Jasmim assumiu um posicionamento conservacionista, defendendo os direitos da comunidade tradicional e utilização sustentável da biodiversidade. Nesse sentido, evidenciamos uma abordagem que procurou aproximar dois campos, quais sejam: ciências naturais e ciências sociais, na compreensão de que a Amazônia, em seus contextos humanos e ambientais, exige, para além do pensamento cartesiano, simplificador e compartimentalizado, abordagem integrada para melhor enfrentamento, do que hoje se configura como um dos desafios socioambientais contemporâneos - a floresta. 
A perda de biodiversidade constitui-se um problema ambiental. Todavia, múltiplos “[...] problemas ambientais modernos foram trazidos à atenção do público por cientistas naturais e sociais, havendo hoje um vasto consenso sobre o fato de que essas questões são também sociais" (VIEIRA; TOLEDO; SANTOS JÚNIOR, 2014, p. 13). Tal configuração adentra o campo da complexidade. Isso porque vários aspectos desdobram-se das dimensões sociais e ambientais, ao mesmo tempo em que se aproximam de outras dimensões: cultural, ética (ambiental e humana), política, entre outras.

Trazemos agora as considerações do Professor Sinos da Mata, no que diz respeito a não viabilidade de extração do taxol, ao afirmar o seguinte:

O processo de extração da casca da espécie Taxus brevifolia, para a produção do taxol não seria a melhor escolha ecológica para a cura do câncer, pois apesar de obter uma excelente eficácia no combate ao câncer, ele não conseguiria suprir a demanda de pessoas atingidas pela doença (PROFESSOR Sinos da Mata).

Sua referência, quanto a não ser a melhor escolha ecológica, pauta-se nas seguintes alegações:

[...] a preservação da espécie estaria ameaçada e, neste caso, a produção da substância interrompida. Os riscos inestimáveis poderiam colocar em risco a sobrevivência da espécie (PROFESSOR Sinos da Mata).

Vemos a preocupação do professor com o risco de extinção da espécie, do mesmo modo que Ceratti (2014, p. 1), ao referir que o “[...] problema, não só do Brasil, mas de todo o mundo, é que o ritmo da extinção das espécies é muito mais rápido do que o da ciência para identificar e descobrir novas espécies”. Para Roos (2012, p. 1497- 1498), os riscos são assim descritos:

A degradação ambiental provocada pelas atividades do homem afeta as condições de sobrevivência das espécies, põe em risco as populações de plantas e consequentemente de animais presentes no ambiente. [...], A cada dia que se passa a lista de animais e plantas a beira da extinção aumenta, desaparecem da superfície terrestre, devido, entre outros fatores, à destruição de ecossistemas, à caça e à captura de indivíduos. A perda da biodiversidade, ainda que não se saiba com exatidão quantas espécies existem na Terra, está acontecendo e cada vez mais se pode perceber tal fato, por que a perda da biodiversidade é um dos problemas ambientais mais graves do planeta.

Ainda, nessa mesma linha de raciocínio, o professor Sinos da Mata trata da questão da exploração predatória e aponta para a necessidade de conservação e respeito aos limites da natureza, chamando a atenção para práticas sustentáveis, quando esclarece que "[...] pra você tirar para o paciente o taxol é preciso destruir duas árvores. Então seria uma forma totalmente predatória para criar uma droga para combater o câncer”. Segundo Siqueira e Morais (2009, p. 2).

Ao mesmo tempo em que degradam o homem, sua qualidade de vida e seu estado de saúde, os padrões de desenvolvimento adotados vêm favorecendo a degradação ambiental por meio da exploração predatória de recursos naturais e poluição, às quais, por sua vez, têm gerado grandes impactos nas condições de saúde e qualidade de vida da população.

Compreendemos que o professor nos chama atenção para os seguintes pontos: ao mesmo tempo em que a tecnologia resolve um problema social, garantindo a sobrevivência humana por meio das descobertas científicas, ela, por outro lado, também gera riscos. Por essa razão, o melhor seria empreender em ações que considerem os limites da natureza, contrárias às ações de exploração predatória, na perspectiva de imprimir um movimento dos processos meramente racionais para aqueles com sensibilidade ambiental.

Então, como Boff (2012, p. 107), consideramos a necessidade de compreender a sustentabilidade segundo os seguintes aspectos:

[...] toda a ação destinada a manter as condições energéticas, físico-químicas que sustentam todos os seres, especialmente a Terra viva, a comunidade de vida e a vida humana, visando sua continuidade e ainda atender às necessidades da geração presente e das futuras, de tal forma que o capital natural seja mantido e enriquecido em sua capacidade de regeneração, reprodução e coevolução.

Assim, por meio dessas lentes percebemos a importância de se romper com um paradigma tradicional, para discutir essas questões dentro de um outro/novo paradigma, o da complexidade, que avalia o todo sem fragmentações, aspectos importantes a serem considerados no ensino e na formação de professores.

Temos, também, a mediação da Professora Margarida, que na sua apreensão aponta o seguinte:

[...] são dois grupos de interesse: indígena e a empresa, com objetivos, ideologias completamente diferentes, ou seja, um pensando no mercado outro na conservação (PROFESSORA Margarida, destaque nosso). 
Com relação a esse pensamento, podemos considerar que o mercado é motivado pelos lucros que movem a constante produção, e que não podemos ficar alheios a esta realidade, uma vez que têm trazido inúmeros passivos para a sociedade. Em realidade,

O mercado farmacêutico movimenta anualmente mais de US\$170 bilhões, e o interesse econômico das grandes empresas em pesquisar e manipular o meio ambiente revela que a diversidade ambiental é bem patrimonial [...]. [...] mas os interesses especulativos das grandes corporações não podem sobrepujar o interesse do povo brasileiro em preservar seu meio ambiente (ROCHA, 2005, p. 54).

Percebemos, assim, a preocupação da professora em destacar essas duas questões importantes: a cultura produtivista do modelo capitalista e a consciência cidadã de conservar os recursos naturais, trazendo a necessidade de se discutir os aspectos objetivos/subjetivos das interações individuais e coletivas, bem como os fatores contribuintes, no referido contexto, ao considerarmos os seguintes aspectos:

[...] pressões de grupos econômicos e, de outro lado, das populações locais mais organizadas, somadas às dificuldades financeiras, operacionais e políticas de fiscalização e manejo dessas áreas, fazem com que a legislação, em parte ou totalmente, não seja cumprida. Dessa forma, têm se multiplicado os casos em que os objetivos de conservação não são cumpridos ao mesmo tempo em que as populações locais são criminalizadas e, simultaneamente, impedidas de explorar os recursos naturais de forma sustentável e garantir sua reprodução sociocultural. Nesse contexto, são beneficiados os grupos que comercializam irregularmente no mercado mais amplo os produtos de extração clandestina, em detrimento da preservação da bio e da sociodiversidade e, finalmente, da credibilidade e aceitação dos ideais de conservação ambiental (ARRUDA, 1999, p.85).

Com isso, temos a considerar que o homem é "peça-chave" para o agravamento dos problemas ambientais, na medida em que insiste em perpetrar ações predatórias, a favor de prerrogativas capitalistas, desconsiderando as perspectivas das futuras gerações. Nesse contexto, a educação constitui-se um dos mecanismos que pode imprimir processos reflexivos sobre o atual estado de coisas, ou seja, problematizar os acontecimentos que conformam a atual crise socioambiental.

Por sua vez, a Professora Acácia mostrou-se contra a exploração da planta, elencando o seguinte argumento:

[...] a exploração de Taxus brevifolia proposta, não acompanha um plano de manejo que assegure sua preservação como recurso de grande importância ecológica e cultural [...] (PROFESSORA Acácia).

A professora chama a atenção para uma exploração sustentável da espécie em questão, e aponta para alternativas, sendo esta o manejo que, em sua opinião, é essencial para a sobrevivência da espécie e a conservação do patrimônio genético, para que se assegure o uso para as gerações vindouras. Nesse sentido, encontra respaldo em Brasil (2000, p. 1), pois a conservação da natureza está imbricada no uso de manejo sustentável, a saber:

O manejo do uso humano da natureza, compreendendo a preservação, a manutenção, a utilização sustentável, a restauração e a recuperação do ambiente natural, para que possa produzir o maior benefício, em bases sustentáveis, às atuais gerações, mantendo seu potencial de satisfazer as necessidades e aspirações das gerações futuras, e garantindo a sobrevivência dos seres vivos em geral.

De fato, para Santilli (2012), o manejo constitui-se uma forma de conservação da espécie, a fim de evitar os riscos futuros provenientes da extinção da mesma. O mesmo autor refere ainda que "[...] a conservação como o desenvolvimento destina-se ao homem. Garantir o bem-estar das gerações de hoje e de amanha é o motivo essencial da conservação" (SANTILLI, 2012, p. 51). Entender essa perspectiva é fundamental, uma vez que colabora para se pensar em sustentabilidade dos recursos naturais, notadamente ao perspectivar um futuro previsível para a humanidade. As discussões sobre as questões de sustentabilidade, por sua vez, precisam ser lançadas em todos os ambientes, e a escola é um destes ambientes, inclusive capaz de favorecer a constituição de cidadãos pela sustentabilidade.

A Professora Orquídea se posicionou a favor da extração do bioativo. Entretanto, refere à dura realidade da relação entre o homem e a natureza, qual seja:

A exploração da natureza pelo homem ela tem que ser encarada naturalmente como o cupim na madeira. Forte isso, mas é verdade, o homem precisa da natureza para tudo gente! Tudo que tem aqui vem da natureza (PROFESSORA Orquídea, destaque nosso).

Contudo, temos que considerar a existência de unidade "[...] entre a sociedade e a natureza, entre a ciência do homem e da natureza. O homem está dentro da natureza, e essa realidade não pode ser abolida. Ela não é um meio exterior ao qual o homem se adapta. O homem é natureza, e a natureza seu mundo" (DIEGUES, 2000, p. 48). Ainda para o mesmo autor, é 
[...] normal a intervenção do homem no curso dos fenômenos e dos ciclos naturais, à semelhança das outras espécies que, segundo suas faculdades, agem sobre as substâncias, as energias e a vida das outras espécies. O que traz problemas não é o fato, mas a maneira como o homem intervém na natureza. Uma natureza pura, não transformada, é um museu, uma reserva, um artifício de cultura como outros [...] o fundamental não é a natureza em si, mas a relação entre o homem e a natureza (DIEGUES, 2000, p. 49).

No mesmo sentido, temos que

Somos escravos de um olhar reducionista, que relega muitas vezes à natureza a função de apenas nos suprir de alimentos, energia, matéria prima e belas paisagens. Dilapidamos o patrimônio natural sem a percepção de que somos parte do planeta, de que o meio ambiente começa no meio da gente, a partir da nossa constituição física, e de que a água, o ar, o solo e a luz solar são elementos fundamentais à manutenção da vida (TRIGUEIRO, 2005, p. 264).

Acreditamos que a professora Orquídea não se afiliou ao capitalismo predatório, naturalizando a utilização perniciosa dos recursos naturais, mas tão somente percebe a impossibilidade de outro modo de desenvolvimento mais benigno à natureza e ao próprio homem, dado o grau de inserção do capitalismo na atual sociedade e, assim, se "rendeu" aos seus efeitos.

A Professora Vitória Régia considera emblemática tal questão. Todas as suas ponderações caminham no sentido de se posicionar contrária à exploração. Vejamos então:

O grupo indígena que defende suas terras e apresenta uma visão global do que a retirada das árvores poderia trazer para sua comunidade e para aquele ecossistema como um todo (PROFESSORA Vitória Régia).

Isso se deve ao fato de que, embora “[...] sendo 'naturalmente ecologista', aos índios se deve reconhecer o crédito histórico de terem remanejado os recursos naturais de maneira branda, provocando poucas perturbações ambientais” (RICARDO, 1996, p. 725).

Consideramos que a Professora Vitória Régia, ao trazer esse aspecto para discussão, "os índios tem visão global", deve ter refletido que a vida dos índios na relação com a natureza não é apenas de exploração e de mera utilização dos recursos naturais, mas é, também, de natureza mítica, na consideração dos valores da natureza no contexto de sua cultura e, por isso, percebem que a extração do bioativo, com depleção da espécie, levará ao desequilíbrio. Trazer questões ligadas à comunidade indígena, notadamente para a formação de professores é difundir a necessidade de valorizar o outro, seu modo de vida, sua singularidade, sua cultura.

A Professora Girassol mostrou-se a favor da extração do taxol, apresentando algumas ponderações, a saber:

Hoje a ciência e a tecnologia podem auxiliar no processo de produção de substâncias sintéticas em laboratório, fazendo com que a espécie vegetal utilizada não entre em extinção, pois a partir da descoberta das moléculas que compõem a substância a mesma pode passar a ser produzida em laboratório (PROFESSORA Girassol).

De fato, hoje, temos a Biologia Sintética, que se propõe a empreender em

[...] possibilidades industriais (energética, química, agrícola e farmacêutica), benéficas tanto para o meio ambiente quanto para a saúde humana: produção de produtos sintéticos, biocombustíveis ecologicamente corretos, métodos de descontaminação ambiental, novos produtos farmacêuticos e métodos terapêuticos, tais como, vacinas, tratamento contra o câncer, combate a infecções e novas drogas sintéticas (SILVA; PAULILLO, 2015, p. 38).

Assim, os estudos publicados, “[...] apesar de hipotéticos, com alguns testes realizados, apresentam relevantes aplicações às indústrias, ao meio ambiente e à saúde humana" (SILVA; PAULILLO, 2015, p. 36). Para os referidos autores, ainda, a Biologia Sintética apresenta desafios importantes, relacionados à ética, ao ambiente, à biossegurança, à falta de regulamentação e ao regime de patenteamentos excessivos, entre outros (SILVA; PAULILLO, 2015).

\section{Considerações finais}

Ao longo do texto, chamamos atenção para as situações adversas provocadas pela crise socioambiental, no sentindo de que tais situações configuram-se riscos à existência e ao prolongamento da vida no planeta. É nesse contexto que, atualmente, muitos desafios socioambientais estão postos à sociedade. Desafios, no sentido de que precisam ser solucionados e/ou mitigados. Neste trabalho, optamos por trabalhar o tema Floresta, por reconhecê-lo como um desafio socioambiental contemporâneo, dado às múltiplas conjunções que têm caracterizado seu "uso" inadequado. 
Recorremos ao cenário amazônico que, além de representar nosso ambiente de vivência, reconhecemo-lo como singular, aos considerarmos sua riqueza em termos de sociobiodiversidade. Ao mesmo tempo, reconhecemos a existência de aspectos deletérios no manejo das florestas, conduzidas pelas atividades capitalistas, que colide com os valores da sobrevivência humana e da defesa da vida em seu sentido lato. De um modo geral, todos nós estamos envolvidos com os desafios socioambientais que se apresentam hodiernamente. Entretanto, ao assumirmos o papel de professor, nossa responsabilidade amplia-se. Isso porque, cabe a nós, professores, apresentar e discutir as implicações dos eventos que configuram a atual crise socioambiental.

Escolhemos fazê-lo em um ambiente de formação continuada de professores. Mas, não uma formação, ao estilo tradicional de ensino/formação. Procuramos proporcionar uma formação que possibilitasse uma compreensão integrada do objeto, pautada pelo paradigma da complexidade, estimulando, assim, sua consideração à luz de múltiplas dimensões inter-relacionadas e de múltiplas referências.

Nesse sentido, desenvolvemos, no contexto de metodologias ativas de ensino e de aprendizagem, um estudo de caso, fictício, mas verossímil, que envolvia um dilema socioambiental, relacionado ao tema floresta, o qual exigia um posicionamento dos professores frente à seguinte decisão: cura ou conservação. Em realidade, a proposição levou em conta a possibilidade de abordagem de questões para além das disciplinas específicas, para adentrar em espaços holísticos, negando o paradigma tradicional, para dar abertura ao paradigma complexo, que analisa o todo com suas partes, e não suas partes isoladamente. Isso porque, entendemos que para enfrentar a atual crise socioambiental requer analisá-la e abordá-la sob o prisma de contextos múltiplos, inter-relacionados, a saber: ambiental, social, econômico, político, religioso, ético, entre outros.

Cabe destacar que nosso objetivo de formação não estava pautado, exclusivamente, na decisão, mas, sim, nos argumentos evocados e a natureza destes. É nesse contexto que podemos afirmar que os posicionamentos dos professores, e respectivos argumentos, manifestaram a integração de conhecimentos de duas áreas: ciências naturais e ciências sociais, aproximando-as. Desse modo, chamando a atenção para a necessidade de abolir o fosso existente entre essas duas áreas. Então, podemos referir que se constituiu um movimento de quebra de paradigma e de diálogos entre disciplinas - um movimento interdisciplinar, uma atitude interdisciplinar, na ponderação do objeto de estudo.

Por sua vez, e não menos importante foi a consideração de aspectos como identidade, cultura e conhecimentos tradicionais. Os posicionamentos esquivaram-se daqueles que exorcizam a alteridade, bem como os que consideram a soberania dos conhecimentos científicos, em relação aos demais. Por outro lado, os professores reconheceram a dificuldade de um agir diferenciado, no sentido de conferir importância a outras razões, em um movimento "da razão instrumental para a razão subjetiva". Nesse agir diferenciado, também se inclui pensar em conservação ao invés de exploração máxima, até a exaustão dos recursos naturais.

Chamaram atenção, também, para a necessidade de considerar as múltiplas unidades sociais que constituem o cenário amazônico, notadamente os indígenas, como os seus modos de vida singulares, suas necessidades, seus direitos e reconhecimento de seus saberes como autênticos. Certamente, tais aspectos remetem, primordialmente, para a necessidade de respeito à diversidade.

Consideramos que as metodologias ativas, na formação de professores, materializadas, aqui, em um estudo de caso, cuja natureza, por si só, apresentou-se de complexa decisão, oportunizou engendrar caminhos que consideraram a multidimensionalidade dos aspectos inerentes à sustentabilidade, as relações que se estabelecem entre Ciência, Tecnologia e Sociedade, a "tendência" de sermos considerados uma sociedade de risco e a importância da adoção do princípio da precaução, no trato das questões socioambientais.

$\mathrm{O}$ percurso formativo, especificamente no que diz respeito às discussões processadas na decisão do caso, adentrou ao campo da complexidade, o que corresponde, de fato, à natureza dos objetos de estudo e de ensino ligados aos desafios socioambientais contemporâneos, a exemplo das florestas. Atualmente, as questões socioambientais mostram-se de difícil abordagem, dado o seu caráter complexo. Assim, pensar a floresta, notadamente a Amazônica, requer abordagem diferenciada, ao consideramos sua natureza multidiversa e, assim, o fizeram os professores, ao apresentarem seus posicionamentos consubstanciados. Evocaram aspectos para além da sua formação específica, integrando conhecimentos, em uma autêntica atitude interdisciplinar na consideração do dilema socioambiental, proposto na formação. As discussões dos professores foram legítimas e seus posicionamentos pertinentes e mostraram-se atuais, ao considerarmos as preocupações que incidem no campo socioambiental.

\section{Referências}

AFONSO, C. M. Sustentabilidade: caminho ou utopia. São Paulo: Annablume, 2006.

ARAGÓN, L. E. Amazônia: destinos. Scientific American, São Paulo: Duetto Editorial, n. 3, 2008.

ARRUDA, R. "Populações Tradicionais" e a proteção dos recursos naturais em unidades de conservação. Ambiente \& Sociedade, São Paulo, a. 2, n. 5, p. 79-92, 1999. 
BATISTA, D. O complexo da Amazônia: análise do processo de desenvolvimento. 2. Ed. Manaus: Editora Valer, Edua e Inpa, 2007.

BEHRENS, M. A.; OLIARI, A. L. T. A evolução dos paradigmas na educação: do pensamento científico tradicional à complexidade. Diálogos Educacionais, Curitiba, v. 7, n. 22, p. 53-66, 2007.

BECKER, B. K. Geopolítica da Amazônia. Estudos Avançados, São Paulo, v.19, n. 53, p. 71-86, 2005.

BIGLIARD, R. V.; CRUZ, G. R. O papel da educação ambiental frente à crise civilizatória atual. Ambiente \& Educação, Rio Grande, v. 12, p.127-141, 2007.

BRASIL. Diretrizes Curriculares Nacionais Gerais da Educação Básica. Ministério da Educação. Secretária de Educação Básica. Diretoria de Currículos e Educação Integral. Brasília: MEC, SEB, DICEI, 2013.

BRASIL. Lei No 9985/2000 - “Regulamenta o art. 225, § 1o, incisos I, II, III e VII da Constituição Federal, institui o Sistema Nacional de Unidades de Conservação da Natureza e dá outras providências” - Brasília, 2000. Disponível em: http://www. mma.gov.br/port/conama/legiabre.cfm?codlegi=322. Acesso em: 7 nov. 2016.

CARSON, R. Primavera silenciosa. Traduzido por Claudia Sant’Anna Martins. 1. Ed. São Paulo: Gaia, 2010.

CARVALHO, A. M. P.; GIL-PÉREZ, D. Formação de professores de ciências: tendências e inovações. São Paulo: Cortez, 2011.

CHASSOT, A. I. Alfabetização científica: questões e desafios para a educação. Ijuí, RS: Ed. Unijuí, 2011.

CERATTI, M. K. Brasil: muito mais flora em risco de extinção do que se pensava. Brasília. 2014. Disponível em: < http:// brasil.elpais.com/brasil/2014/11/14/politica/141 5920874_248706.html>. Acesso em: 5 nov. 2016.

CRESWELL, J. W. Projeto de pesquisa: método qualitativo, quantitativo e misto. Porto Alegre: Artmed, 2010.

CONSERVAÇÃO INTERNACIONAL. Investigando a biodiversidade: guia de apoio aos educadores do Brasil/ Conservação Internacional, WWF- Brasil, Instituto Supereco; tradução original, Débora Agria de Oliveira Melo, Sylvia Oliveira Nocetti. Belo Horizonte, Brasília: Conservação Internacional; Instituto Supereco; WWF- Brasil, 2010. Disponível em: $<\underline{\text { http://www. }}$ conservation.org/global/brasil/publicacoes/ Documents/investigan do_a_bi odiversidade.pdf>. Acesso em: 29 mar. 2016.

DIEGUES, A. C. Etnoconservação da natureza: enfoques alternativos. In: (Org). Etnoconservação: novos rumos para a conservação da natureza. São Paulo: Hucitec, Núcleo de Apoio à Pesquisa sobre Populações Humanas e Áreas Úmidas Brasileiras, USP, 2000.

ESTEBAN, M. S. Pesquisa qualitativa em educação: fundamentos e tradição. Porto Alegre: Artmed, 2010.

FERREIRA, A. M. M.; SALATI, E. Forças de transformação do ecossistema amazônico. Estudos Avançados, São Paulo, v. 19 , n. 54, p. 25-44, 2005.

FLACH, C. R. C.; BEHRENS, M. A. Paradigmas educacionais e sua influência na prática pedagógica. In: Congresso Nacional de Educação da PUCPR, EDUCERE, 8; Congresso Ibero-Americano sobre Violências nas Escolas - CIAVE,3. Curitiba, Paraná, 6 a 9 de outubro de 2008. Anais eletrônicos... Disponível em: <http://www.pucpr.br/eventos/educere/educere2008/ anais/pdf/541_365.pdf>. Acesso em: 15 jan. 2017.

FONSECA NETO, S. N.; FREITAS, N. M. S.; FREITAS, N. M. S. Uma carta para o futuro: constructos sobre (in)sustentabilidade. Ciência e Natura, Santa Maria, v. 39 n.1, p. 133-141, 2017.

GANEM, R. S; DRUMMOND, J. A. Biologia da conservação: as bases científicas da proteção da biodiversidade. In: (ORG.). Conservação da biodiversidade: legislação e políticas públicas. Brasília: Câmara dos Deputados, Edições Câmara, 2011. (Série Memória e Análise de Leis, n. 2).

GARCIA, E. S. Biodiversidade, Biotecnologia e Saúde. Cadernos de Saúde Pública, Rio de Janeiro, v. 11, n. 3, p. 491-494, 1995. 
GONÇALVES, V. B. O princípio da precaução e a gestão dos riscos ambientais: contribuições e limitações dos modelos econômicos. Ambiente \& Sociedade, São Paulo, v. 16, n. 4, p. 121-140, 2013.

GONÇALVES, C. W. P. Amazônia e Amazônias. 2. Ed. São Paulo: Contexto, 2009.

HATHAWAY, D. A biopirataria no Brasil In: BENSUSAN, N. Seria melhor mandar ladrilhar? Biodiversidade - como, para que e por quê. São Paulo: Peirópolis; Brasília, DF: Ed Universidade de Brasília, 2008.

HOSANNAH, J. de J. M. O papel da OTCA na proteção da Amazônia. XVI Curso de Especialização em Relações Internacionais, Brasília 2015. Disponível em: < $\underline{\text { http://bdm.unb.br/bitstream/10483/11500/1/2015 }}$

JulianadeJesusMachadoHosannah.pdf. Acesso em: 17 Ago. 2017.

IMBERNÓN, F. Formação continuada de professores. Porto Alegre: Artmed, 2010.

JOLLIVET, M.; PAVÉ, A. O meio ambiente: questões e perspectivas para a pesquisa. In: VIEIRA, P. F.; WEBER, J. (Org.). Gestão de recursos naturais renováveis e desenvolvimento: novos desafios para pesquisa ambiental. São Paulo: Cortez, 2002.

KAGEYAMA, P. Y. Biodiversidade e Biopirataria: contradição entre a biodiversidade e a pobreza no mundo. In: AZEVEDORAMOS, C. et al. Amazônia e desenvolvimento sustentável. Rio de Janeiro: Fundação Konrad Adenauer, 2010. p. 23 -33.

KOHLHEPP, G. Conflitos de interesse no ordenamento territorial da Amazônia brasileira. Estudos Avançados, São Paulo, v.16, n. 45, p. 37- 61, 2002.

LEFF, E. (Coord.). A complexidade ambiental. São Paulo: Cortez, 2010.

Aposta pela vida: imaginação sociológica e imaginários sociais nos territórios ambientais do Sul. Petrópolis, RJ: Vozes, 2016.

Saber ambiental: sustentabilidade, racionalidade, complexidade, poder. Petrópolis, RJ: Vozes, 2012.

LIMA, D. POZZOBON, J. Amazônia socioambiental. Sustentabilidade ecológica e diversidade social. Estudos Avançados, São Paulo, v. 19, n. 54, p. 45-76, 2005.

MALDANER, O. A. A formação inicial e continuada de professores de química. 2d. Ijuí: Ed. Unijuí, 2003.

MINAYO, M. C. de. S. Trabalho de campo: contexto de observação, interação e descoberta. In: método e criatividade. Petrópolis, RJ: Vozes, 2016. p. 56-71. (Série Manuais acadêmicos). Pesquisa social: teoria,

MIRRA, A. L. V. Direito ambiental: o princípio da precaução e sua aplicação judicial. Revista de Direito Ambiental, Santa Catarina, n. 21, janeiro/março de 2001. Disponível em: <http://www.egov.ufsc.br/portal/sites/default/files/anexos/26866268681-PB.pdf.>. Acesso em: 9 jul. 2015.

MORAES, R. Uma tempestade de luz: a compreensão possibilitada pela análise textual discursiva. Ciência \& Educação, Bauru, v. 9, n. 2, p. 191-211, 2003.

MORAN, E. F. Meio ambiente e floresta. São Paulo: Editora SENAC, 2010. (Série Meio Ambiente, 11).

NASCIMENTO, E. P. do. Trajetória da sustentabilidade: do ambiental ao social, do social ao econômico. Estudos Avançados, São Paulo, v. 26, n.74, p. 51-64, 2012.

QUEIROZ, E. D; PLÁCIDO, P. O. Um olhar para a formação de professores a partir da educação ambiental crítica. In: ENDIPE - Encontro Nacional de Didática e Práticas de Ensino, 16. UNICAMP, Campinas, 2012. Anais eletrônicos ... Disponível em: <http://www.infoteca.inf.br/endipe/smarty/templates/arquivos_templat es/arquivos_template/upload_arquivos/acervo/ docs/2880p.pdf>. Acesso em: 20 ago. 2015. 
RIBAS, M. H., CARVALHO, M. A. de, ALONSO, M.; Formação continuada de professores e mudança na prática pedagógica. In: ALONSO, M. (Org.). Prática docente: teoria e prática. São Paulo: Pioneira, 2003.

RICARDO, C. A.. A Sociobiodiversidade Nativa Contemporânea no Brasil. In: Povos indígenas no Brasil: 1991/1995. São Paulo: Instituto Socioambiental, 1996.

ROOS, A. A biodiversidade e a extinção das espécies. Revista Eletrônica em Gestão, Educação e Tecnologia Ambiental, Santa Maria, v. 7, n. 7, p. 1494-1499, 2012.

ROCHA, F. A. N. G. Regulamentação jurídica do acesso à biodiversidade. Revista do Curso de Direito, Nova Lima, v. 3 , n. 5, p. 52-70, 2005.

SÁ, L. QUEIROZ, S. L. Estudo de caso no ensino de química. Campina, SP: Átomo, 2010.

SACHS, I. Desenvolvimento: includente, sustentável, sustentado. Rio de Janeiro: Garamond, 2008.

SANTILLI, J. Socioambientalismo e novos direitos. São Paulo: Peirópolis. 2012.

SILVA, J. B. G.; PAULILLO, L. C. M. S. Biologia sintética: possibilidades e desafios. Revista da Biologia, São Paulo, v. 14, n. 1, p. $33-39,2015$.

SILVA, M. das G. Questão ambiental e desenvolvimento sustentável: um desafio ético-político ao serviço social. São Paulo: Cortez, 2010.

SIQUEIRA, M. M.; MORAIS, M. S. de. Saúde coletiva, resíduos sólidos urbanos e os catadores de lixo. Ciência e Saúde Coletiva, Rio de Janeiro, v.14, n. 6, p. 2115-2122, 2009.

STAHEL, A, W. Capitalismo e entropia: os aspectos ideológicos de uma contradição e a busca de alternativas sustentáveis. In: CAVALCANTE, C. (Org). Desenvolvimento e natureza: estudos para uma sociedade sustentável. 5. Ed - São Paulo: Cortez; Recife PE: Fundação Joaquim Nabuco, 2009. p.104-127.

SCHWINGEL, T. C. P. G.; UHMANN, R. I. M.; HERMEL, E. do E. S. As (im)possíveis relações ambientais versus conceituais em livros didáticos de ciências do $6^{\circ}$ ano do ensino fundamental. Contexto \& Educação, Editora Unijuí, Rio Grande do Sul, a. 31, n. 100, p. 56-30, 2016.

TAVOLARO, S. B. F. Ação comunicativa. In: FERRARO JÚNIOR, L. A. Encontros e caminhos: formação de educadoras(es) ambientais e coletivos educadores. Brasília: MMA, Diretoria de Educação Ambiental, 2005. p.15-25.

TRIGUEIRO, A. Mundo sustentável: abrindo espaço na mídia para um planeta em transformação. São Paulo: Globo Editora, 2005.

TRISTÃO, M. A educação ambiental na formação de professores: redes de saberes. São Paulo: Annablume; Vitória; Facitec, 2004.

UNESCO. Década das Nações Unidas para um desenvolvimento sustentável, 2005-2014. Documento final do esquema internacional de implementação. Brasília, DF: UNESCO, 2005.

VASCONCELOS, E. R.; FREITAS, N. M. S. Discursos de Professores sobre a Amazônia: implicações para o ensino de ciências. In: Encontro Nacional de Pesquisa em Educação em Ciências, 8; Congreso Iberoamericano de Investigación en Enseñanza de las Ciencias, 1. 2011, Campinas. Atas do VIII ENPEC; I CIEC. Rio de Janeiro: ABRAPEC, 2011. Disponível em: <http:// www.nutes.ufrj.br/abrapec/viiienpec/resumo

s/R0473-1.pdf. Acesso em: 15 nov. 2016.

; O paradigma da sustentabilidade e a abordagem CTS: mediações para o ensino de ciências. Amazônia. Revista de Educação em Ciências e Matemáticas, Belém, v. 9, n. 17, p. 89-108, jul. 2012/dez. 2012. 
; FERREIRA, D. T.; VALENTE, J. A. S.; FREITAS, N. M. S. Educar para a justiça social e ambiental: que questões pensar no contexto do ensino e da formação de professores de ciências? Revista Brasileira de Pesquisa em Educação em Ciências, São Paulo, v. 14, n. 2, p. 245-254, 2014.

VIANA, V. As florestas e o desenvolvimento sustentável na Amazônia. Manaus: Valer, 2006.

VIEIRA, I. C. G.; TOLEDO, P. M. de; SANTOS JUNIOR, R. A. O. Ambiente e Sociedade na Amazônia: uma abordagem interdisciplinar. Rio de Janeiro: Garamond, 2014.

WATANABE-CARAMELLO, G.; KAWAMURA, m. R. D. Uma educação na perspectiva ambiental crítica, complexa e reflexiva. Revista Brasileira de Pesquisa em Educação em Ciências, Minas Gerais, v. 14, n. 2, p. 255-264, 2014.

\section{Lidiane Amaral Barbosa}

Programa de Pós-Graduação em Educação em Ciências e Matemáticas Universidade Federal de Pará, PA, Brasil Email:lidibarbosa2010@hotmail.com Participação do autor:

\section{Elinete Oliveira Raposo}

Instituto de Educação Científica e Matemática -

Universidade Federal de Pará, PA, Brasil

Email: elineterr@gmail.com

Participação do autor:

\section{Nadia Magalhães da Silva Freitas}

Programa de Pós-Graduação em Educação em Ciências e Matemáticas Instituto de Educação Científica e Matemática -

Universidade Federal de Pará, PA, Brasil

Email: nadiamsf@yahoo.com.br

Participação do autor: 